Article

\title{
The Interaction Pathway in the Mechano-Ultrasonically Assisted and Carbon-Nanotubes Augmented Nickel-Aluminum System
}

\author{
Khachik Nazaretyan ${ }^{1}$, Hasmik Kirakosyan ${ }^{1, *}$, Marieta Zakaryan ${ }^{1}$, Larisa Abovyan ${ }^{1}$, Olga Volobujeva ${ }^{2}$ and \\ Sofiya Aydinyan 1,2
}

1 Laboratory of Macrokinetics of Solid State Reactions, A.B. Nalbandyan Institute of Chemical Physics NAS RA, P. Sevak 5/2, Yerevan 0014, Armenia; khachik.nazaretyan@ichph.sci.am (K.N.); marieta@ichph.sci.am (M.Z.); larisa@ichph.sci.am (L.A.); sofiya.aydinyan@taltech.ee (S.A.)

2 Department of Mechanical and Industrial Engineering, Tallinn University of Technology, Ehitajate 5, 19086 Tallinn, Estonia; olga.volobujeva@taltech.ee

* Correspondence: hasmik.kirakosyan@ichph.sci.am; Tel.: +374-94181606

\section{check for}

updates

Citation: Nazaretyan, K.; Kirakosyan,

H.; Zakaryan, M.; Abovyan, L.;

Volobujeva, O.; Aydinyan, S.

The Interaction Pathway in the

Mechano-Ultrasonically Assisted and

Carbon-Nanotubes Augmented

Nickel-Aluminum System. Metals

2022, 12, 436. https://doi.org/

$10.3390 /$ met12030436

Academic Editor: Ruslan

R. Balokhonov

Received: 21 January 2022

Accepted: 26 February 2022

Published: 1 March 2022

Publisher's Note: MDPI stays neutral with regard to jurisdictional claims in published maps and institutional affiliations.

Copyright: (C) 2022 by the authors. Licensee MDPI, Basel, Switzerland. This article is an open access article distributed under the terms and conditions of the Creative Commons Attribution (CC BY) license (https:// creativecommons.org/licenses/by/ $4.0 /)$.

\begin{abstract}
The influence of mechano-ultrasonic activation (MUA) and nano-additives (carbon nanotubesCNT) on the interaction pathway of nickel-aluminum powder mixture at high heating rates was investigated. The optimum conditions of the mechano-ultrasonic activation, along with the phase and structure formation peculiarities of nickel-aluminum and nickel-aluminum-carbon nanotubes mixtures by thermal analysis method, the so-called high-speed temperature scanner (HSTS), were found out. The optimum duration of mechanical and ultrasonic activation aiming to achieve homogeneous distribution in the agitated mixtures was determined. A shift in characteristic temperatures of MUA mixtures by the influence of both heating rate and ultrasound on the $\mathrm{Ni}+\mathrm{Al}$ interaction pathway for the mechano-activated $(1,3,5 \mathrm{~min})$ and $1 \mathrm{wt} \%$ CNT containing mixtures was observed. The formation patterns of $\mathrm{NiAl}+\mathrm{Ni}_{3} \mathrm{Al}$ mixture or pure $\mathrm{NiAl}$ phase was manifested according to the interaction mechanism (depending on solid-liquid or solid-solid state of intermediates). The effective activation energy values for the $\mathrm{Ni}+\mathrm{Al}$ exothermic reactions of all studied systems were determined by the isoconversional method of Kissinger.
\end{abstract}

Keywords: mechano-ultrasonic activation; carbon nanotubes; high heating rate; activation energy

\section{Introduction}

Nickel-aluminum intermetallics, encompassing the compositional region between $40 \%$ and $80 \%$ of nickel, have attracted considerable interest owing to a favorable combination of properties, such as high melting point, low weight, high resistance to corrosion, and high-temperature strength [1-3]. The mechanical activation (MA) [4,5] and self-propagating high-temperature synthesis (SHS) are the most widely investigated techniques [6-8] among the versatile methods for manufacturing nickel aluminides. MA has already emerged as one of the productive and mature techniques for the solid-state synthesis of the nanocrystalline intermetallics uniform by the phase composition [9]. Additionally, MA is utilized to attain grain refinement, hardening and alloying through secondary phases, which have been found to be effective strategies to improve the mechanical behavior of these intermetallic compounds. Therefore, the utilization of MA allows us to overcome the challenges that arise in the melting or casting processes of nickel aluminides $[10,11]$. Mechanically activated SHS (MASHS) is a type of combustion process where preliminary mechanical activation significantly changes the structures of the SHS precursors. As a result of ball milling, an increase in the reserved energy of the system occurs and leads to a shorter ignition time and reaction initiation temperature; in addition, the evolution of nanostructures is favored [12].

A number of experimental and some theoretical works [13-16] are devoted to the influence of MA on SHS processes of the Ni-Al system. Recently, it was shown that ultrasound 
treatment has a dramatic influence on the morphology of inorganic solids [17-19]. However, the intensive ultrasonic activation of the initial $\mathrm{Ni}-\mathrm{Al}$ charge was considered in few works $[20,21]$. In particular, the surface area of the sonically treated particles considerably increases compared to untreated ones. Intensive treatment of $\mathrm{Al}$ under ultrasound causes the development of sponge-like particulates, stabilized by a thin layer of metal oxide. This sponge-like matrix would promote the reactivity of charge due to increased specific surface area. An experimental and theoretical study into the effect of intensive ultrasonic activation of the powder mixture on the phase and structure formation of $\mathrm{Ni}-\mathrm{Al}$ intermetallics in the combustion wave will make it possible to obtain new scientific patterns and open up wide opportunities for a targeted impact on the fine and homogeneous microstructure of the final product. Therewith, a gap in the regulation of SHS processes is that they usually occur in a narrow range of parameters (size of initial particles, composition, sample's relative density, etc.) and cannot be controlled after initiation. Thus, it is pertinent to design a novel SHS process to grant in-situ control over the structure and features of the target compounds. From this perspective, the inclusion of nano-additives in the initial mixture and preliminary mechanical and ultrasonic activation (MUA) become promising [22].

Carbon nanotubes (CNT) were chosen as the nano-additive owing to their superior mechanical characteristics, such as axial elastic stiffness and tensile strength, which can be employed for structural applications. Embedding carbon nanoparticles in nanocomposites and homogeneous dispersion in ductile and lightweight metals, for instance, in the aluminum matrix, may contribute to enhanced mechanical properties. However, the low affinity of CNT to Al hinders dispersion and strong interfacial binding. MA and UA would help overcome this issue, together with the addition of metal (for example, nickel) bonding to $\mathrm{sp}^{2}$ hybridized carbon and making the interfaces between CNT and nanoparticles comparatively stronger. On the other hand, the utilization of carbon nanotubes will play the role of the refiner for the metals' oxidized surfaces, in particular, for aluminum, and promote the interaction process.

Extreme conditions in the SHS wave (elevated temperatures and fast self-heating of substances in the combustion wave) impede the disclosure of interaction pathways in the SHS process and optimization of synthesis conditions. To tackle the challenge, the process in the $\mathrm{Ni}-\mathrm{Al}$ system was modelled at guided conditions, in particular, at a programmed heating routine via tuning the interaction over the time and approximation of conditions to the combustion process, by the thermal analysis method, namely using a high-speed temperature scanner (HSTS) [23-25]. The influences of MUA ( $t_{\mathrm{UA}}=0-55 \mathrm{~min}, \mathrm{t}_{\mathrm{MA}}=1-5 \mathrm{~min}$ ) and heating rates on the kinetics, phase, and microstructure evolution pathway of $\mathrm{Ni}-\mathrm{Al}$ and carbon-nanotubes augmented $\mathrm{Ni}-\mathrm{Al}$ systems were examined. By changing the heating rates of systems from 100 to $2600 \mathrm{~K} \mathrm{~min}^{-1}$, we succeeded in achieving homogeneity in the microstructure and complete phase formation in the $\mathrm{Ni}-\mathrm{Al}$ system through the addition of CNT to the initial mixture and mechano-ultrasonic activation. The HSTS results were complemented by the characterization of phase and microstructure transformations based on SEM/EDS and XRD analyses results of quenched intermediates and calculations of kinetic parameters. This study aimed to disclose the interaction kinetics of the systems under study, unravel the relevance of MUA treatment and utilization of carbon nanotubes, as well as deduce the most favorable conditions (UA and MA duration, ignition temperature, heating rate, heating temperature, etc.) for the preparation of nickel aluminides.

\section{Materials and Methods}

Nickel (NPK, Yekaterinburg, Sverdlovsk region, Russia, particle size $<10 \mu \mathrm{m}$, purity $99.8 \%$ ) and aluminum (ASD-4, Kyiv, Ukraine, particle size $<40 \mu \mathrm{m}$, purity $99.9 \%$ ) powders were used as raw materials, and carbon nanotubes were used as nano-additives (CNT, from tens of nanometers to several microns in size produced by [22]). The mechanical activation of the $\mathrm{Ni}$ and $\mathrm{Al}$ green mixture (1:1 molar ratio) was carried out in a planetary ball mill (RETSCH PM-100, Haan, Germany) at different durations (1-5 min), using $10 \mathrm{~mm}$-diameter steel balls as crushing-milling media, and $\mathrm{m}_{\text {ball }} / \mathrm{m}_{\text {material }}=20: 1$ ratio. Dry mixing in the air 
was performed at a rotational speed of $500 \mathrm{rpm}$. The nano-additive $(\mathrm{m}(\mathrm{CNT})=1 \mathrm{wt} \%)$ was mixed with the mechanically activated mixture in a ceramic mortar for $15 \mathrm{~min}$. Ultrasonic activation of the powder mixture was performed with an ultrasonic cleaner (Stegler 6DT, $40 \mathrm{kHz}$, Shenzhen, China) with a duration of 1-55 min in ethanol medium. The agitated samples were dried at $373 \mathrm{~K}$ for $10 \mathrm{~h}$.

As-prepared mixtures were subjected to high-speed heating using a high-speed temperature scanner (HSTS, Institute of Chemical Physics, Yerevan, Armenia, $\mathrm{V}_{\mathrm{h}}=100-2600 \mathrm{~K} \mathrm{~min}^{-1}$, $\left.\mathrm{T}_{\max }=1573 \mathrm{~K}\right)$. Thermal analysis equipment aimed to elucidate the role of the heating rate and temperature at non-isothermal conditions on the interaction mechanism in the system under study. This method is based on the electrically controlled high-speed heating of the sample under study and continuous recording of electrical power, as well as the sample's temperature during the process. In addition to recording the temperature curves, the process was discontinued at various distinctive stages of the interaction, and quenched samples were subjected to phase and microstructural examinations. When the heating process was interrupted, up to $12,000 \mathrm{~K} \mathrm{~min}^{-1}$ cooling rate was achieved, impeding further possible interactions over the cooling process.

The principle operation of the HSTS [23-26] device was based on the direct electrical heating of a cell made of a thin metal sheet containing a reactive mixture (Figure 1). The latter $(50 \mathrm{mg})$ was poured into a thin envelope made from nickel (100 $\mu \mathrm{m}$ in thickness), installed in the reactor, and attached to electrical contacts. First, the reactor was vacuumed and filled with $0.1 \mathrm{MPa}$ inert gas (argon, purity $>99.98 \%$ ). The maximum heating temperature during the measurements did not exceed $1573 \mathrm{~K}$.

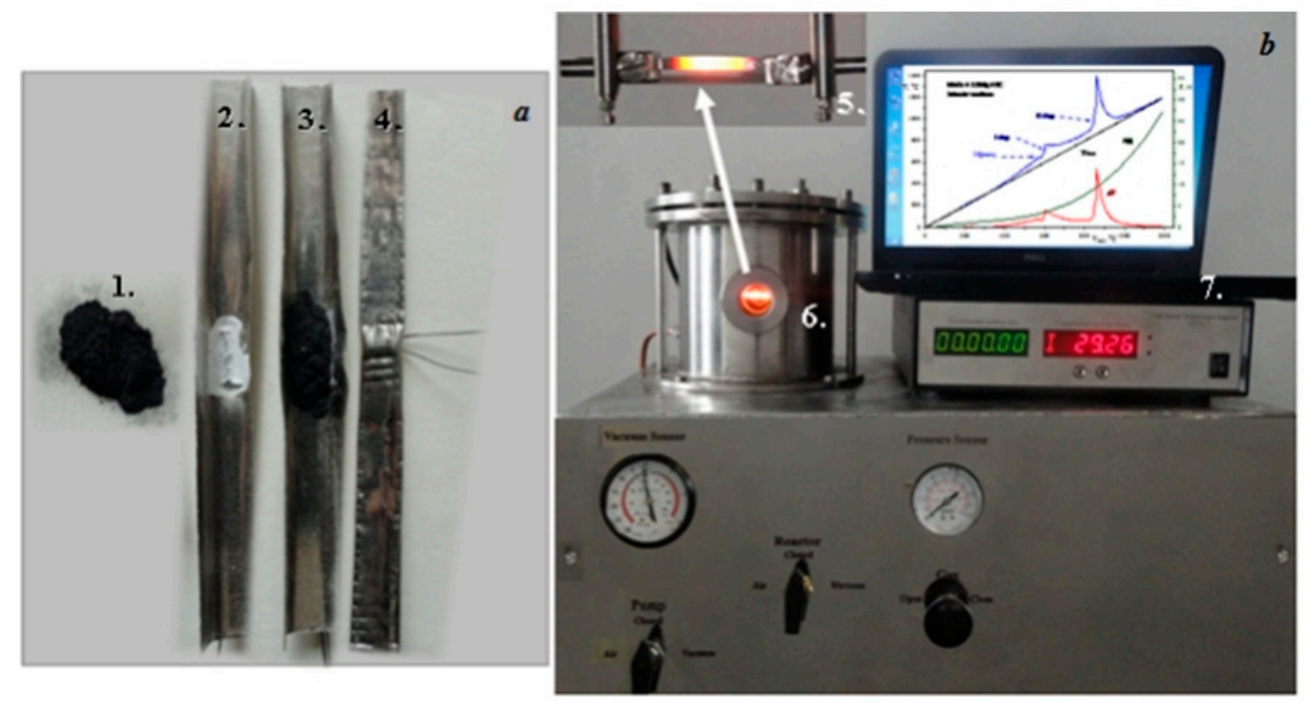

Figure 1. The experimental steps for the kinetic studies using a high-speed temperature scanner. (a) envelope-heater with reactive mixture under study; (b) reaction chamber and controller: 1 reactive mixture, 2-boat made from nickel foil, 3-powder mixture in Ni boat, 4-envelope with mixture and thermocouple wire, 5-heated sample, 6-reaction chamber, 7-electronic unit and PC for control and registration [26].

The calculation of effective activation energy value for the reaction between nickel and aluminum was performed by the isoconversional method suggested by Kissinger [27]. The essence of methodology is the registration of the temperature shift that corresponds to the maximum advance on the heating curve at a given heating rate. The following expression (Equation (1)) is usually used to determine the effective activation energy value: 


$$
\ln \left(\frac{V_{h}}{(T *)^{2}}\right)=\ln A-\frac{E}{R}\left(\frac{1}{T *}\right)
$$

where $V_{h}$ is the experimental heating rate $\left(\mathrm{K} \mathrm{min}^{-1}\right), T^{*}$-temperature on the inert curve that corresponds to the maximum advance on the heating profile, $A$-constant for a specific reaction, $E$-effective activation energy $\left(\mathrm{kJ} \mathrm{mol}^{-1}\right), R$-universal gas constant.

XRD data on the phase composition of the intermediates and final products were collected by Bruker diffractometer (D5005, Billerica, MA, USA) with monochromatic $\mathrm{CuK} \alpha$ radiation $(\lambda=1.5406 \AA)$. JCPDS-ICDD database [28] was used to process XRD data and identify the intermetallic materials from XRD patterns (Ni_PDF \#65-2865 (Fm-3m), Al_\#652869 (Fm-3m), NiAl_PDF 65-0431 (Pm-3m), Ni 3 Al 65-0430_(Pm-3m)). The microstructural examinations were performed on the scanning electron microscopes (SEM, Prisma E and FE-SEM, Zeiss Evo MA15, Oberkochen, Germany) equipped with an EDS detector.

\section{Results and Discussion}

\subsection{Ultrasonic Activation of $\mathrm{Ni}+\mathrm{Al}$ Powder Mixture}

Earlier, the influence of ultrasonic activation was investigated on the phase composition and microstructure transformation of the initial non-activated and mechano-activated $\mathrm{Ni}+\mathrm{Al}$ mixtures of a 1:1 molar ratio. In order to determine the optimum UA duration, mechano-activated $\mathrm{Ni}+\mathrm{Al}$ mixture $\left(\mathrm{t}_{\mathrm{MA}}=1 \mathrm{~min}\right)$ was subjected to ultrasonic activation from 1 to $55 \mathrm{~min}$. Prior to and after the activation, microstructural and EDS analyses of the corresponding samples were performed (Figure S1a,b). According to the results, in the case of ultrasonic activation for $25 \mathrm{~min}$, a homogeneous, evenly distributed mixture of metal powders was obtained. This is evidenced also by the presence of sufficient intensities of the characteristic peaks of the constituents $(\mathrm{Ni}, \mathrm{Al})$ in the EDS spectrum and almost identical atomic percentages of metals in the selected microstructure with an area of $50 \mu \mathrm{m}$.

According to the determined optimum conditions of UA, the non-mechano-activated and mechano-activated (for 1-5 $\mathrm{min}$ ) mixtures, as well as the mixtures containing $1 \mathrm{wt} \%$ $\mathrm{CNT}$, were subjected to ultrasonic activation for $25 \mathrm{~min}$.

UA significantly affected the microstructural characteristics of the initial mixtures. As can be seen from Figure 2a,b, ultrasonic agitation in mechano-activated mixtures promoted the homogenization of the powder. The particle size reduction, phase segregation, and redistribution on the surface of particles given by sonomechanical action, along with homogenization of the powder mixture, occurred at up to 3 min MA and 25 min UA conditions (Figure 2c). However, a longer duration of MA caused agglomeration mainly of the ductile aluminum phase, and, despite UA treatment, agglomerates were not sufficiently dispersed (Figure 2d).

Higher magnification SEM images demonstrate the influence of both UA and MA on the metal's behavior in the mixture (Figure S2). In particular, 5 min MA leads to agglomeration of powder regardless of the UA treatment (Figure S2), and, in terms of the reduction in particle size, the UA treatment was beneficial for the mixtures mechanoactivated for up to $3 \mathrm{~min}$ (Figure 2c,d). 

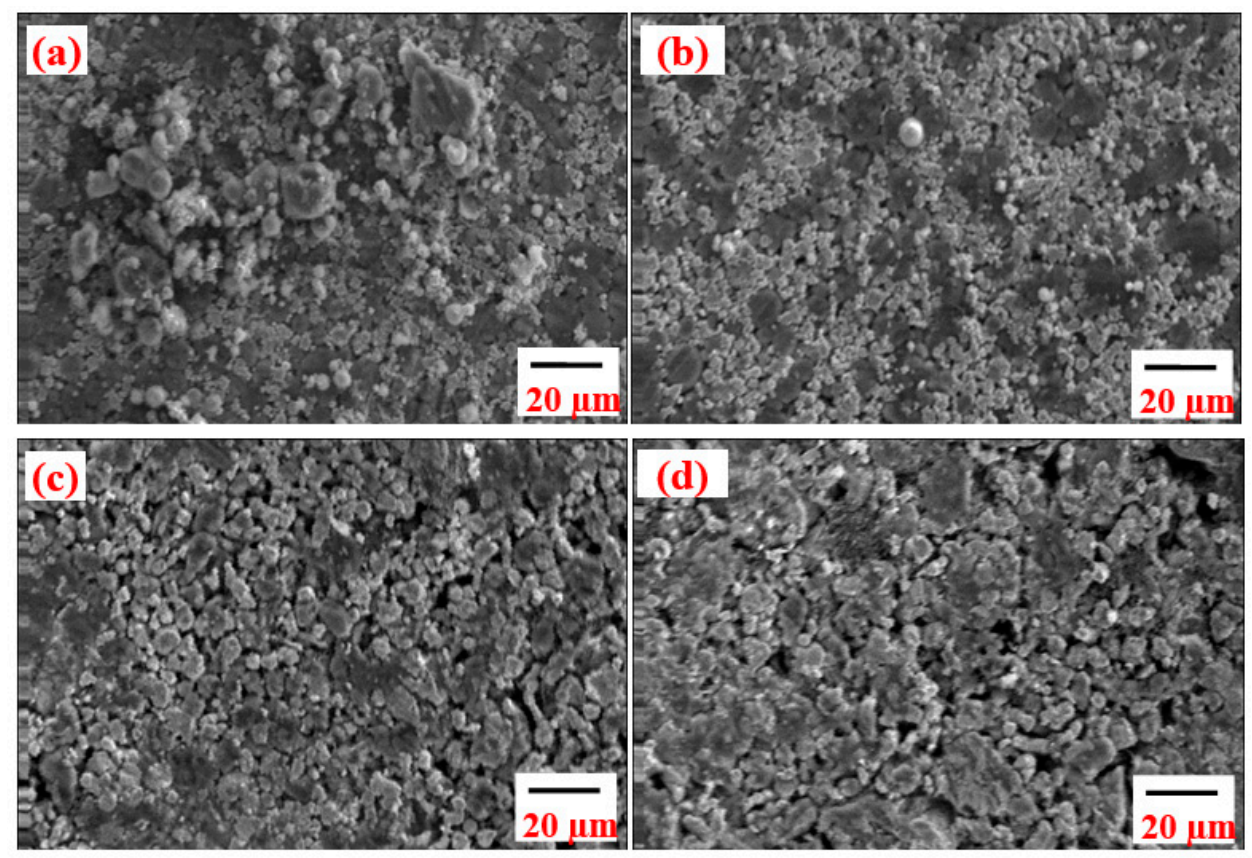

Figure 2. $\mathrm{SEM}$ images of $\mathrm{Ni}+\mathrm{Al}$ mixture; $(\mathbf{a}) \mathrm{t}_{\mathrm{MA}}=0 \mathrm{~min}, \mathrm{t}_{\mathrm{UA}}=0 \mathrm{~min},(\mathbf{b}) \mathrm{t}_{\mathrm{MA}}=0 \mathrm{~min}, \mathrm{t}_{\mathrm{UA}}=25 \mathrm{~min}$, (c) $\mathrm{t}_{\mathrm{MA}}=3 \mathrm{~min}, \mathrm{t}_{\mathrm{UA}}=25 \mathrm{~min},(\mathbf{d}) \mathrm{t}_{\mathrm{MA}}=5 \mathrm{~min}, \mathrm{t}_{\mathrm{UA}}=25 \mathrm{~min}$.

According to the microstructural analysis results, the carbon nanotubes augmented powder after the simultaneous mechanical and ultrasonic activation was characterized, firstly, by particle size reduction, dispersion, and separation ( $\mathrm{t} \leq 3 \mathrm{~min})$, and then agglomerate formation ( $t>3 \mathrm{~min}$ ) (Figure 3 ). The influence of UA is more expressed on MA mixtures compared to non-mechano-activated mixtures.

Therefore, it can be argued that the effect of ultrasonic activation on the reduction in particle size in the presence of nanoadditives is also noticeable for up to 3 min of mechano-activated mixtures.
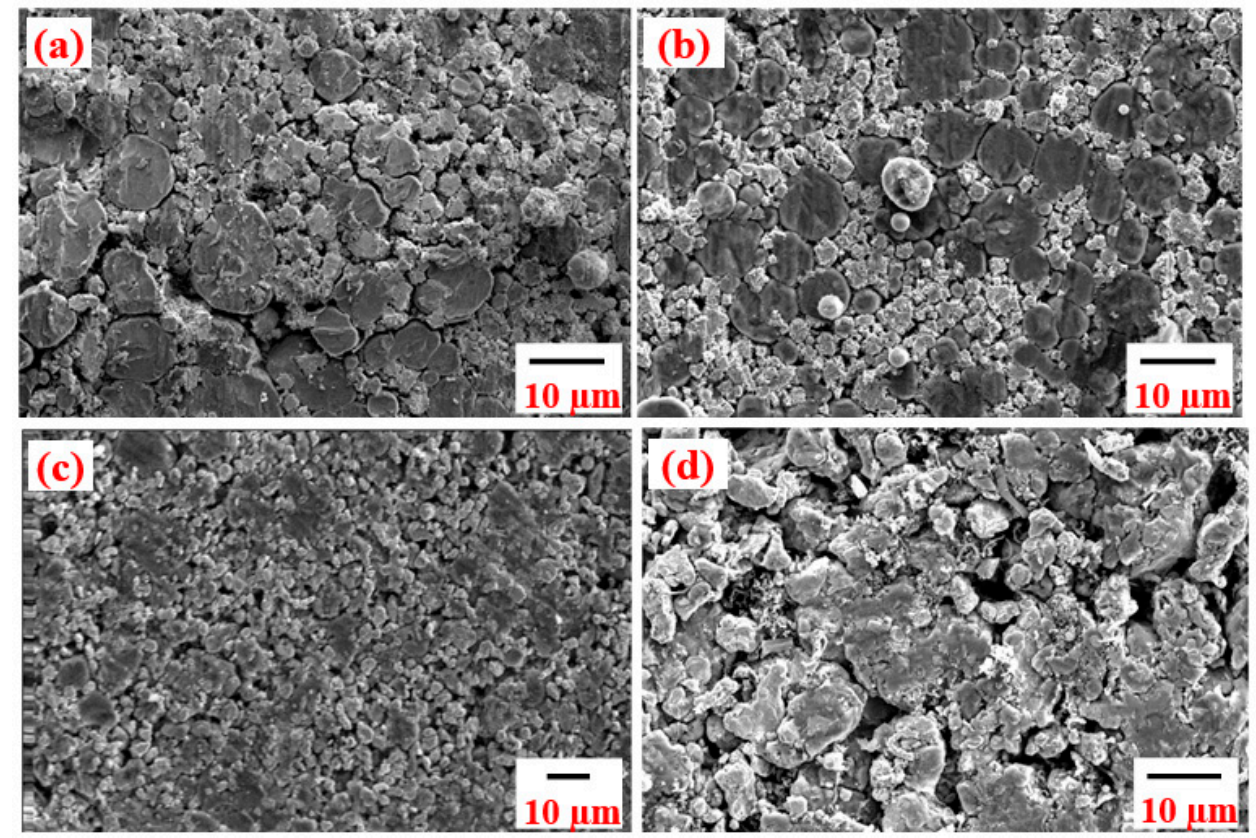

Figure 3. SEM micrographs of $\mathrm{Ni}+\mathrm{Al}+1 \mathrm{wt} \%$ CNTmixtures; (a) $\mathrm{t}_{\mathrm{MA}}=0 \mathrm{~min}, \mathrm{t}_{\mathrm{UA}}=0 \mathrm{~min}$; (b) $\mathrm{t}_{\mathrm{MA}}=0 \mathrm{~min}, \mathrm{t}_{\mathrm{UA}}=25 \mathrm{~min} ;(\mathbf{c}) \mathrm{t}_{\mathrm{MA}}=3 \mathrm{~min}, \mathrm{t}_{\mathrm{UA}}=25 \mathrm{~min}$; $(\mathbf{d}) \mathrm{t}_{\mathrm{MA}}=5 \mathrm{~min}, \mathrm{t}_{\mathrm{UA}}=25 \mathrm{~min}$. 
According to the results of the XRD analysis, the duration of mechano-activation did not change the phase composition of the UA mixtures, but the intensity and width of the characteristic peaks were modified. Based on the latter, the average size in the vertical direction of crystal for the component metals was calculated (Figure 4) according to Scherrer's formula (Equation (2)):

$$
\mathrm{D}=\frac{K \cdot \lambda}{\beta \cdot \cos \theta}
$$

$\mathrm{D}$ is the dimension of the crystallite, $\mathrm{K}$ is a constant, which usually has a value between 0.89 and 0.94 and depends on the used peak fitting function, $\beta$ is the half width at half maximum of the peak, $\theta$ is the scattering angle, $\lambda$ is the wavelength $(0.154 \mathrm{~nm})$.

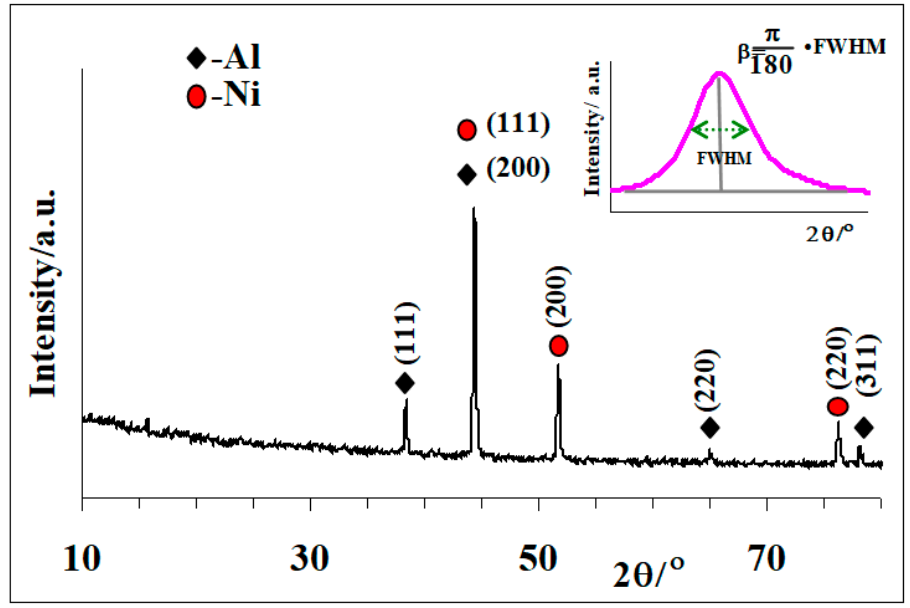

Figure 4. XRD pattern of $5 \mathrm{~min}$ activated $\mathrm{Ni}+\mathrm{Al}$ mixture after $25 \mathrm{~min}$ ultrasonic activation.

From the comparison of samples without UA and UA agitated for $25 \mathrm{~min}$, it is obvious that the simultaneous action of both mechanical and ultrasonic activation is more effective for grain dispersion than the separate application of each of these procedures. Moreover, for the mechanically activated mixtures for up to $3 \mathrm{~min}$, a decrease in the size of nickel and aluminum crystallites was observed under the influence of UA (Table 1).

Table 1. Lattice parameters and average size of crystals according to Scherer's equation for non-UA $\left(\mathrm{Ni}^{*}, \mathrm{Al}^{*}\right)$ and 25 min $\mathrm{UA}$ subjected systems.

\begin{tabular}{ccccccc}
\hline & \multirow{2}{*}{ \#ICDD } & Lattice Parameter, $\AA$ & \multicolumn{4}{c}{ Average Size of Crystals, $\mathbf{n m}$} \\
\cline { 3 - 7 } & & $\mathbf{a}=\mathbf{b}=\mathbf{c}$ & $\mathbf{t}=\mathbf{0} \mathbf{~ m i n}$ & $\mathbf{t}=\mathbf{1} \mathbf{~ m i n}$ & $\mathbf{t}=\mathbf{3} \mathbf{~ m i n}$ & $\mathbf{t}=\mathbf{5}$ min \\
\hline $\mathrm{Ni}$ & $\# 652865$ & 3.52 & 33 & 27 & 21 & 34 \\
\hline $\mathrm{Al}$ & $\# 652869$ & 3.74 & 42 & 26 & 26 & 38 \\
\hline $\mathrm{Ni}^{*}$ & $\# 652865$ & 3.52 & 33 & 28 & 23 & 24 \\
\hline $\mathrm{Al}^{*}$ & $\# 652869$ & 3.74 & 38 & 38 & 36 & 35 \\
\hline
\end{tabular}

\subsection{The Influence of Heating Rate on the MUA Ni-Al and Ni-Al-1 wt\% CNT Systems}

The impact of ultrasonic activation on the non-mechano-activated and mechanoactivated $\mathrm{Ni}+\mathrm{Al}$ and $\mathrm{Ni}+\mathrm{Al}+1 \mathrm{wt} \% \mathrm{CNT}$ mixtures has been studied over a broad range of heating speeds ranging from 100 to $2600 \mathrm{~K} \mathrm{~min}^{-1}$. Single-stage exothermic interaction corresponding to $\mathrm{Ni}+\mathrm{Al}$ reaction was observed in all studied mixtures. In the studied interval of heating rates, in the UA agitated non-mechano-activated (Figure $5 \mathrm{a}, \mathrm{t}_{\mathrm{MA}}=0 \mathrm{~min}$, $\mathrm{t}_{\mathrm{UA}}=25 \mathrm{~min} ; \mathrm{T}_{\mathrm{O}}=943 \mathrm{~K}$ ) and for up to $1 \mathrm{~min}$ mechano-activated mixtures (Figure 5a, $\left.\mathrm{t}_{\mathrm{MA}}=1 \mathrm{~min}, \mathrm{t}_{\mathrm{UA}}=0 \mathrm{~min} ; \mathrm{T}_{\mathrm{o}}=938 \mathrm{~K}, \mathrm{t}_{\mathrm{MA}}=1 \mathrm{~min}, \mathrm{t}_{\mathrm{UA}}=25 \mathrm{~min} ; \mathrm{T}_{\mathrm{o}}=933 \mathrm{~K}\right)$, the 
interaction began after the aluminum melting. At a longer MA duration ( $t_{\mathrm{MA}} \geq 3 \mathrm{~min}$ ), the interaction initiatedat the same temperature and proceeded prior to the melting temperature of aluminum, regardless of the heating rate (Figure 5a, Table 2). In CNT augmented $\mathrm{Ni}+$ $\mathrm{Al}$ mixtures, the reaction initiation temperature decreased with the increasing MA duration (Table 2, Figure 5b). Withthe presence of nano-additives in the nickel-aluminum mixtures under the influence of $\mathrm{UA}$, the interaction occurred before the melting of aluminum, i.e., by solid+solid mechanism in both non-mechano-activated and mechano-activated mixtures. As a general pathway for all the study's mixtures, one may observe a decrease in the exothermicity of the main interaction as a result of the change in the system energy state (expansion of microcavities, friction, grain deformation, creation of new surfaces, etc.) occurring during the MA processing (Figures $5 \mathrm{a}, \mathrm{b}$ and 6 ).
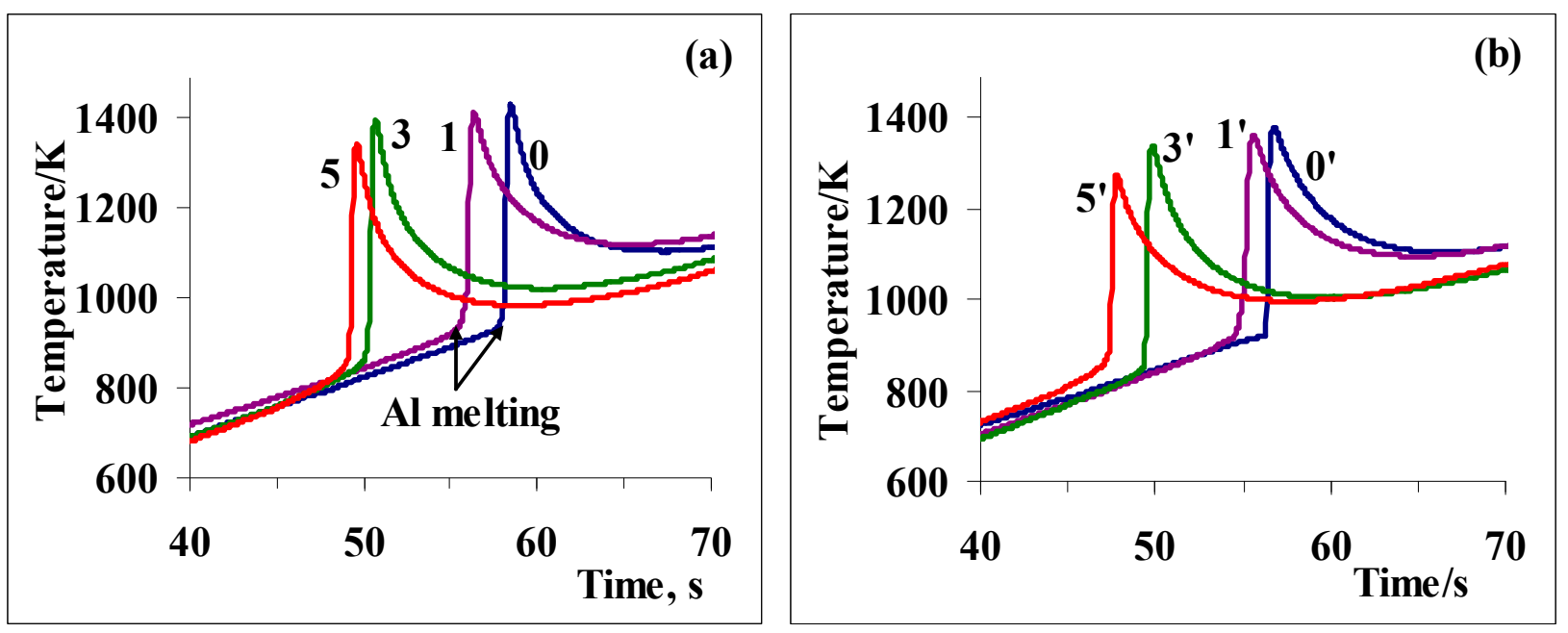

Figure 5. The interaction behavior of UA agitated $\mathrm{Ni}+\mathrm{Al}\left(0 \_\mathrm{t}_{\mathrm{MA}}=0 \mathrm{~min}, 1 \mathrm{t}_{\mathrm{MA}}=1 \mathrm{~min}, 3 \_\mathrm{t}_{\mathrm{MA}}=\right.$ $\left.3 \mathrm{~min}, 5 \_\mathrm{t}_{\mathrm{MA}}=5 \mathrm{~min}\right)(\mathbf{a})$ and $\mathrm{Ni}+\mathrm{Al}+1 \mathrm{wt} \% \mathrm{CNT}\left(0^{\prime} \mathrm{t}_{\mathrm{MA}}=0 \mathrm{~min}, 1^{\prime}{ }_{-} \mathrm{t}_{\mathrm{MA}}=1 \mathrm{~min}, 3^{\prime} \_\mathrm{t}_{\mathrm{MA}}=3 \mathrm{~min}\right.$ $\left.5^{\prime}{ }_{-}{ }_{\mathrm{MA}}=5 \mathrm{~min}\right)(\mathbf{b})$ mixtures on the heating curves, $\mathrm{t}_{\mathrm{UA}}=25 \mathrm{~min}, \mathrm{~V}_{\mathrm{h}}=600 \mathrm{~K} \mathrm{~min}^{-1}$.

Table 2. Characteristic temperatures $(\mathrm{K})$ of various $\mathrm{Ni}+\mathrm{Al}$ mixtures.

\begin{tabular}{|c|c|c|c|c|c|c|c|c|c|}
\hline \multirow[t]{2}{*}{$\mathrm{T}_{\mathrm{MA}}, \mathrm{min}$} & \multicolumn{3}{|c|}{$\mathbf{N i}+\mathbf{A l}$} & \multicolumn{3}{|c|}{$\mathrm{Ni}+\mathrm{Al}, \mathrm{t}_{\mathrm{UA}}=25 \mathrm{~min}$} & \multicolumn{3}{|c|}{$\begin{array}{c}\mathrm{Ni}+\mathrm{Al}+1 \% \mathrm{CNT} \\
\mathrm{t}_{\mathrm{UA}}=25 \mathrm{~min}\end{array}$} \\
\hline & To & $\mathbf{T}^{*}$ & $\mathbf{T}_{\max }$ & To & $\mathrm{T}^{*}$ & $\mathrm{~T}_{\max }$ & To & $\mathrm{T}^{*}$ & $T_{\text {max }}$ \\
\hline 0 & 933' & 938 & 1428 & $943^{\prime}$ & 943 & 1423 & 923 & 943 & 1373 \\
\hline 1 & 933' & 938 & 1443 & 933' & 933 & 1393 & 923 & 928 & 1353 \\
\hline 3 & 893 & 903 & 1413 & 903 & 903 & 1373 & 888 & 893 & 1333 \\
\hline 5 & 873 & 883 & 1323 & 878 & 888 & 1333 & 873 & 883 & 1273 \\
\hline
\end{tabular}

Solid-solid and solid-liquid interactions were differentiated ('denotes the interaction by solid-liquid mechanism) according to the plateau observed on the thermograms and based on the reaction initiation temperature in the MUA Ni-Al systems (UA duration was kept constant-25 min).

Enforced by the mutual MUA influence, the heating curves are shifted to a lower temperature range, demonstrating the beneficial effect of MUA on the initiation of interaction (Figure 6). 


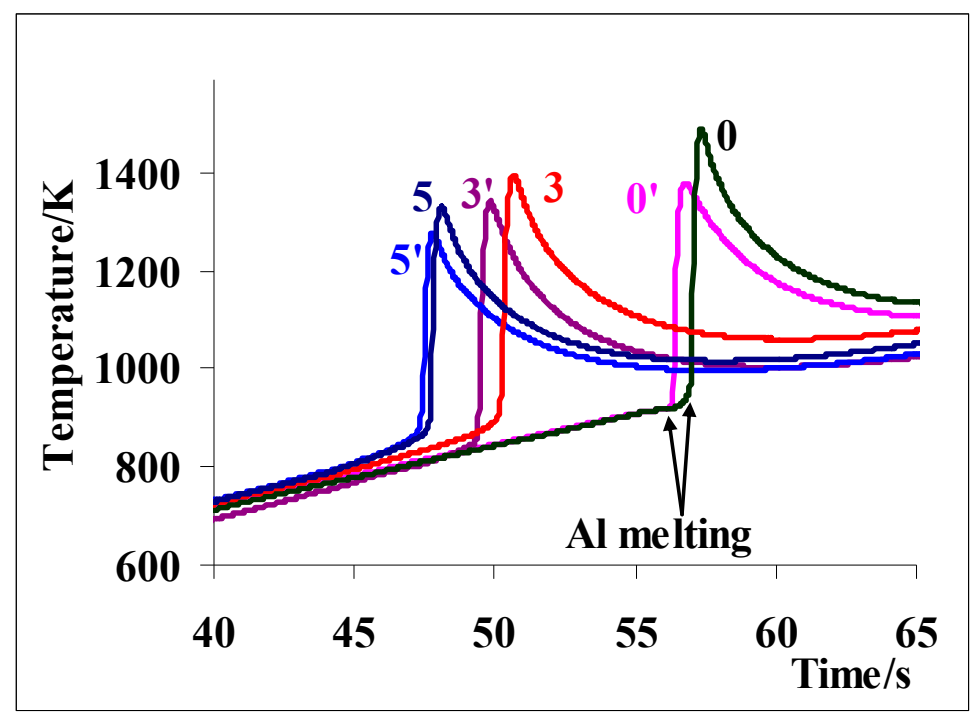

Figure 6. The influence of MUA on the heating thermograms of $\mathrm{Ni}+\mathrm{Al}+1 \% \mathrm{CNT}$ mixtures, $\mathrm{t}_{\mathrm{UA}}=25 \mathrm{~min}, \mathrm{~V}_{\mathrm{h}}=600 \mathrm{Kmin}^{-1}: 0_{-} \mathrm{t}_{\mathrm{MA}}=0 \mathrm{~min}, 0^{\prime} \_\mathrm{t}_{\mathrm{MA}}=0 \mathrm{~min}+\mathrm{UA} ; 3_{-} \mathrm{t}_{\mathrm{MA}}=3 \mathrm{~min}, 3^{\prime} \_\mathrm{t}_{\mathrm{MA}}=$ $3 \mathrm{~min}+\mathrm{UA} ; 5 \_\mathrm{t}_{\mathrm{MA}}=5 \mathrm{~min}, 5^{\prime} \_\mathrm{t}_{\mathrm{MA}}=5 \mathrm{~min}+\mathrm{UA}$.

\subsection{The Phase Formation Patterns of the MUA Ni+Al Systems}

The mechanism of interaction in the mechano-activated, as well as ultrasonically activated, $\mathrm{Ni}+\mathrm{Al}$ and $\mathrm{Ni}+\mathrm{Al}+1 \% \mathrm{CNT}$ mixtures depends on the temperature at which the exothermic reaction begins, in particular, on whether the process occurs with molten or solid aluminum. In the case of the nickel-aluminum interaction starting before the melting of aluminum $(<933 \mathrm{~K})$, the reaction was proceeded by the solid+solid mechanism, and immediately after the process, there were two phases in the XRD pattern of the quenched products: $\mathrm{NiAl}$ along with a trace amount of $\mathrm{Ni}_{3} \mathrm{Al}$. A further rise in temperature (up to $1573 \mathrm{~K}$ ) promoted the development of a single-phase $\mathrm{NiAl}$ phase by the interaction of $\mathrm{Ni}_{3} \mathrm{Al}$ with unreacted aluminum (considering the initial composition of metals 1:1 ratio). When the process started after the aluminum melting $(>933 \mathrm{~K})$, the reaction proceeded according to the solid + liquid mechanism. The molten aluminum dissolves nickel completely, and immediately after the exothermic reaction, there was a stoichiometric single-phase $\mathrm{NiAl}$ in the diffractogram of the quenched sample. Particularly, at a heating rate of $600 \mathrm{~K} \mathrm{~min}^{-1}$, in $\mathrm{UA}$ agitated non-mechano-activated and 1 min mechano-activated $\mathrm{Ni}+\mathrm{Al}$ and $\mathrm{Ni}+\mathrm{Al}+$ $1 \%$ CNT mixtures, the reaction started after melting of aluminum $\left(\mathrm{Ni}+\mathrm{Al} \_\mathrm{t}_{\mathrm{MA}}=0 \mathrm{~min}\right.$, $\mathrm{t}_{\mathrm{UA}}=25 \mathrm{~min}, \mathrm{~T}=943 \mathrm{~K} ; \mathrm{t}_{\mathrm{MA}}=1 \mathrm{~min}, \mathrm{t}_{\mathrm{UA}}=25 \mathrm{~min}, \mathrm{~T}=933 \mathrm{~K} ; \mathrm{Ni}+\mathrm{Al}+1 \% \mathrm{CNT}_{\mathrm{A}} \mathrm{t}_{\mathrm{MA}}=0 \mathrm{~min}$, $\mathrm{t}_{\mathrm{UA}}=25 \mathrm{~min}, \mathrm{~T}=943 \mathrm{~K} ; \mathrm{t}_{\mathrm{MA}}=1 \mathrm{~min}, \mathrm{t}_{\mathrm{UA}}=25 \mathrm{~min} ; \mathrm{T}=928 \mathrm{~K}$, Table 2). At a higher duration of MA (2-5 min) in mechano-activated mixtures at a heating rate of $600 \mathrm{~K} \mathrm{~min}^{-1}$, the process began before the aluminum melted; the reaction was proceeded only by the solid+solid mechanism, leading to the formation of $\mathrm{NiAl}$ and $\mathrm{Ni}_{3} \mathrm{Al}$ phases (Figures 7 and 8). Thereby, all CNT containing $\mathrm{Ni}+\mathrm{Al}$ mixtures under UA decreased if the reaction initiation temperature occurred: the utilization of carbon nanotubes played the role of the refiner for the metals' oxidized surfaces, in particular, for aluminum, and promoted the interaction process. Moreover, in the 1 min mechano-activated mixtures, a change in the mechanism complemented by the emergence of different $\mathrm{Ni}-\mathrm{Al}$ phases was observed. This was confirmed by XRD patterns of the products quenched at characteristic temperatures (Figures 7 and 8). 

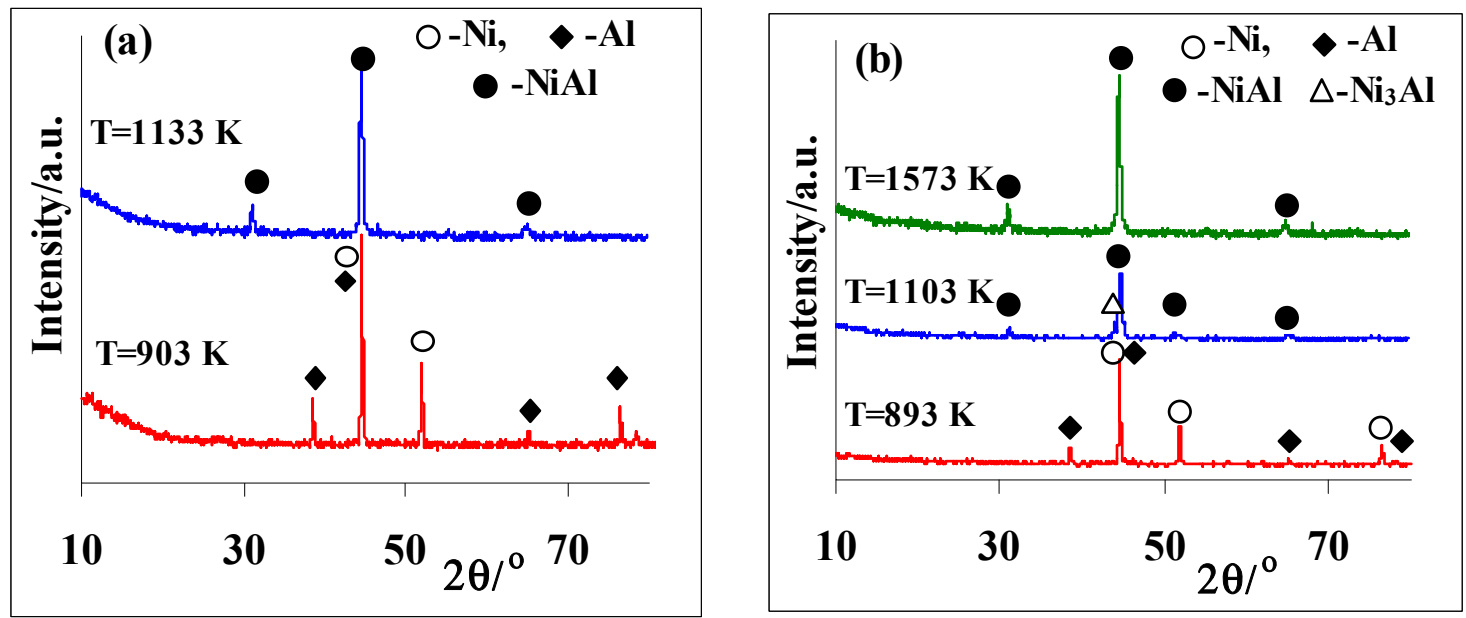

Figure 7. XRD patterns of the products derived from 1 min mechano-activated $\mathrm{Ni}+\mathrm{Al}(\mathbf{a})$ and $\mathrm{Ni}+$ $\mathrm{Al}+1 \% \mathrm{CNT}(\mathbf{b})$ mixtures, $\mathrm{t}_{\mathrm{UA}}=25 \mathrm{~min}, \mathrm{~V}_{\mathrm{h}}=600 \mathrm{~K} \mathrm{~min}^{-1}$.
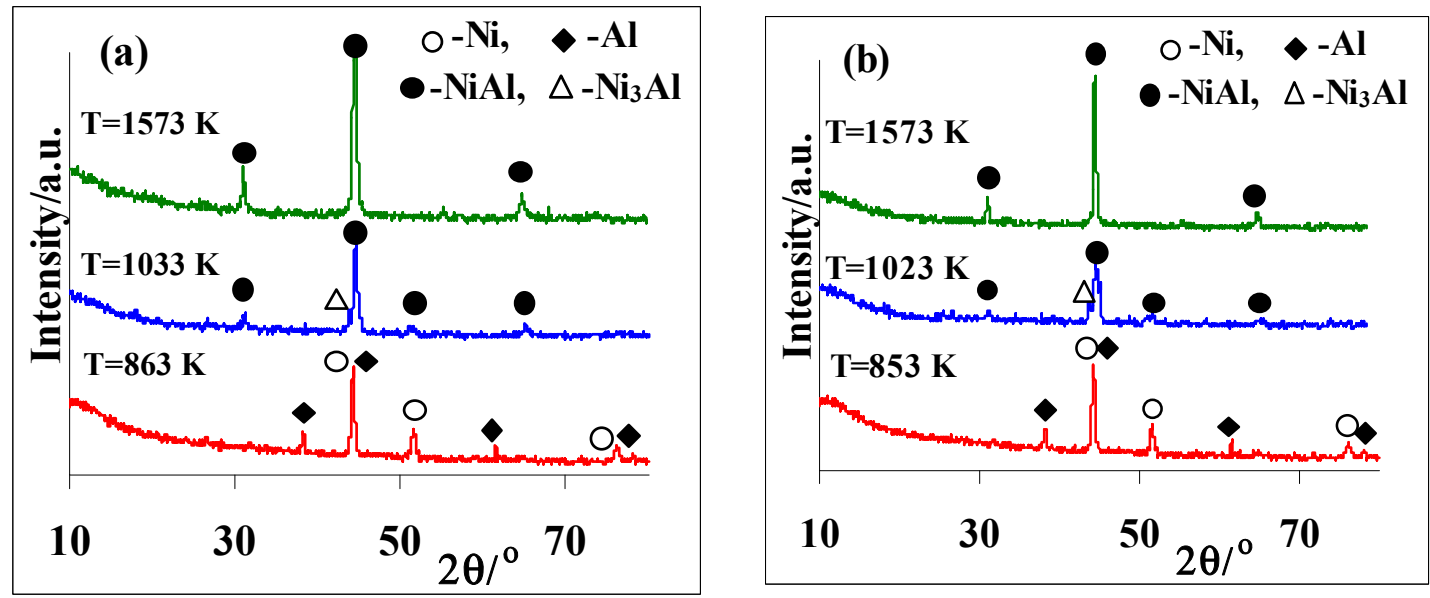

Figure 8. XRD patterns of the products derived from 5 min mechano-activated $\mathrm{Ni}+\mathrm{Al}(\mathbf{a})$ and $\mathrm{Ni}+$ $\mathrm{Al}+1 \% \mathrm{CNT}(\mathbf{b})$ mixtures, $\mathrm{t}_{\mathrm{UA}}=25 \mathrm{~min}, \mathrm{~V}_{\mathrm{h}}=600 \mathrm{~K} \mathrm{~min}^{-1}$.

Microstructural examinations of the quenched samples after the exothermic interaction at $873 \mathrm{~K}$ (without grinding or sieving) in the $\mathrm{Ni}-\mathrm{Al}$ and $\mathrm{Ni}-\mathrm{Al}-1 \mathrm{wt} \% \mathrm{CNT}$ mixtures revealed the formation of powder comprising agglomerates from 5 to $50 \mu \mathrm{m}$ (Figure 9).
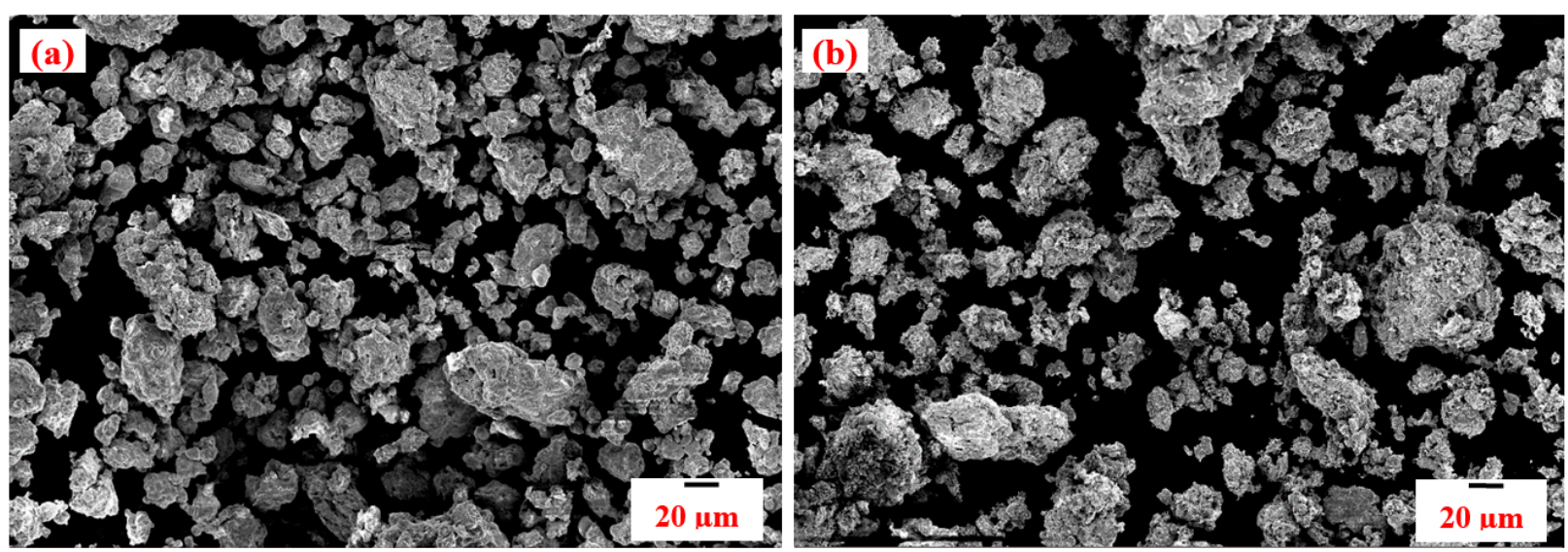

Figure 9. SEM images of samples quenched at $873 \mathrm{~K}$ from $\mathrm{Ni}+\mathrm{Al}(\mathbf{a})$ and $\mathrm{Ni}+\mathrm{Al}+1 \% \mathrm{CNT}$ (b) systems; $\mathrm{V}_{\mathrm{h}}=600 \mathrm{~K} \mathrm{~min}^{-1}, \mathrm{t}_{\mathrm{MA}}=5 \mathrm{~min}, \mathrm{t}_{\mathrm{UA}}=25 \mathrm{~min}$. 
A higher magnification image (Figure 10a) of the $\mathrm{Ni}+\mathrm{Al}$ system showed the spongelike alloy formation under MUA processing, where the agglomerates consisted of up to $50 \mathrm{~nm}$ particles (Figure 10b). Samples quenched at $1473 \mathrm{~K}$ underwent sintering (Figure 10c). In some places, exfoliation of the sintered alloy was observed (Figure 10d).
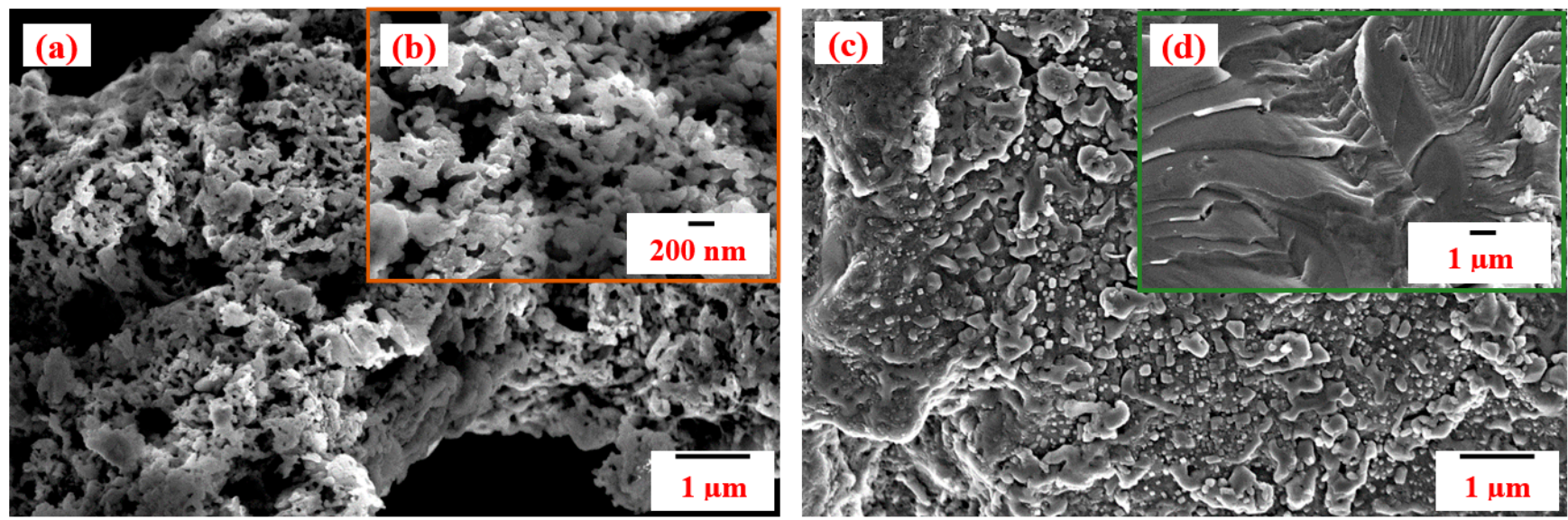

Figure 10. SEM imagesof quenched samples from the $\mathrm{Ni}+\mathrm{Al}$ system at $873 \mathrm{~K}(\mathbf{a}, \mathbf{b})$ and $1473 \mathrm{~K}(\mathbf{c}, \mathbf{d})$, $\mathrm{V}_{\mathrm{h}}=600 \mathrm{~K} \mathrm{~min}^{-1}, \mathrm{t}_{\mathrm{MA}}=5 \mathrm{~min}, \mathrm{t}_{\mathrm{UA}}=25 \mathrm{~min}$.

SEM images of CNT containing samples quenched at $873 \mathrm{~K}$ demonstrate the presence of finer particles in contrast to just the $\mathrm{Ni}+\mathrm{Al}$ system (Figure 11a,b), revealing the positive effect of nanotubes on the alloy microstructure refinement under UA agitation. Sintered counterparts derived from CNT containing samples, i.e., samples quenched at $1473 \mathrm{~K}$, exhibit an alloy microstructure with well-defined grains and needles of nm size (Figure 11c,d).
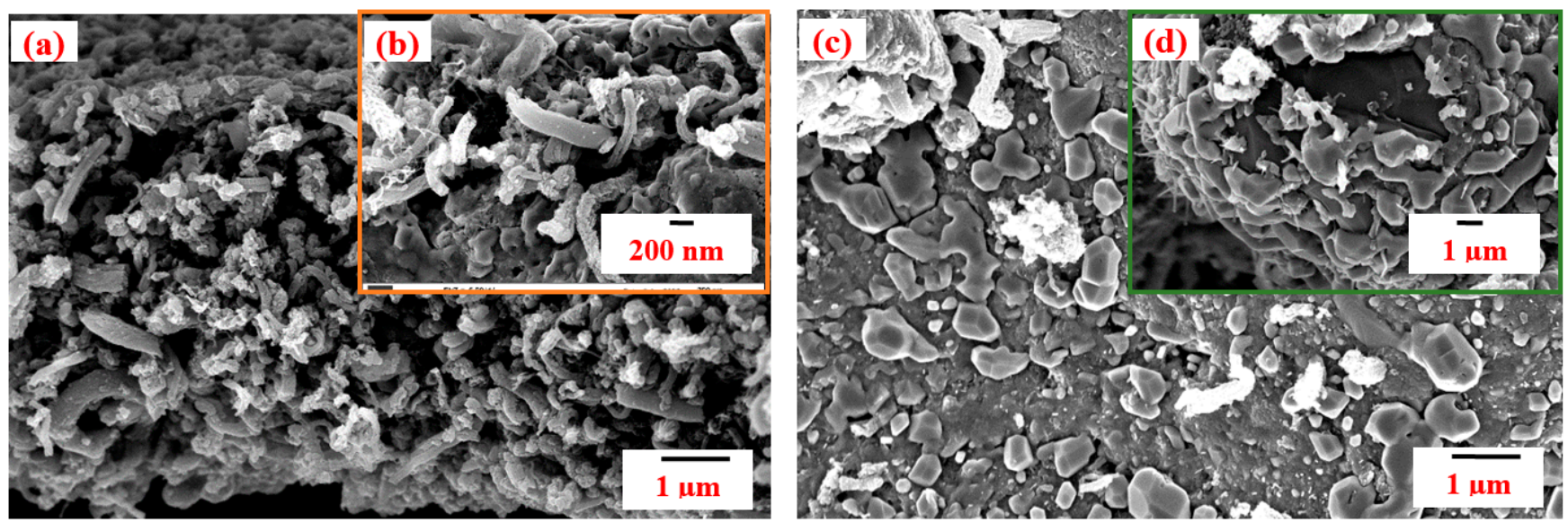

Figure 11. SEM images of quenched samples from the $\mathrm{Ni}+\mathrm{Al}+1 \% \mathrm{CNT}$ system at $873 \mathrm{~K}(\mathbf{a}, \mathbf{b})$ and $1473 \mathrm{~K}(\mathrm{c}, \mathrm{d}), \mathrm{V}_{\mathrm{h}}=600 \mathrm{~K} \mathrm{~min}^{-1}, \mathrm{t}_{\mathrm{MA}}=5 \mathrm{~min}, \mathrm{t}_{\mathrm{UA}}=25 \mathrm{~min}$.

To confirm the phase composition of the formed product complementary to XRD examinations, EDS analysis was performed. The ratio of metals in the micrometer range is about 1:1, corresponding to composition of the NiAl intermetallic (Figures 12 and S3). It was not possible to detect 3:1 composition by EDS caused by a trace amount of the aforementioned phase (detected by XRD analysis). 

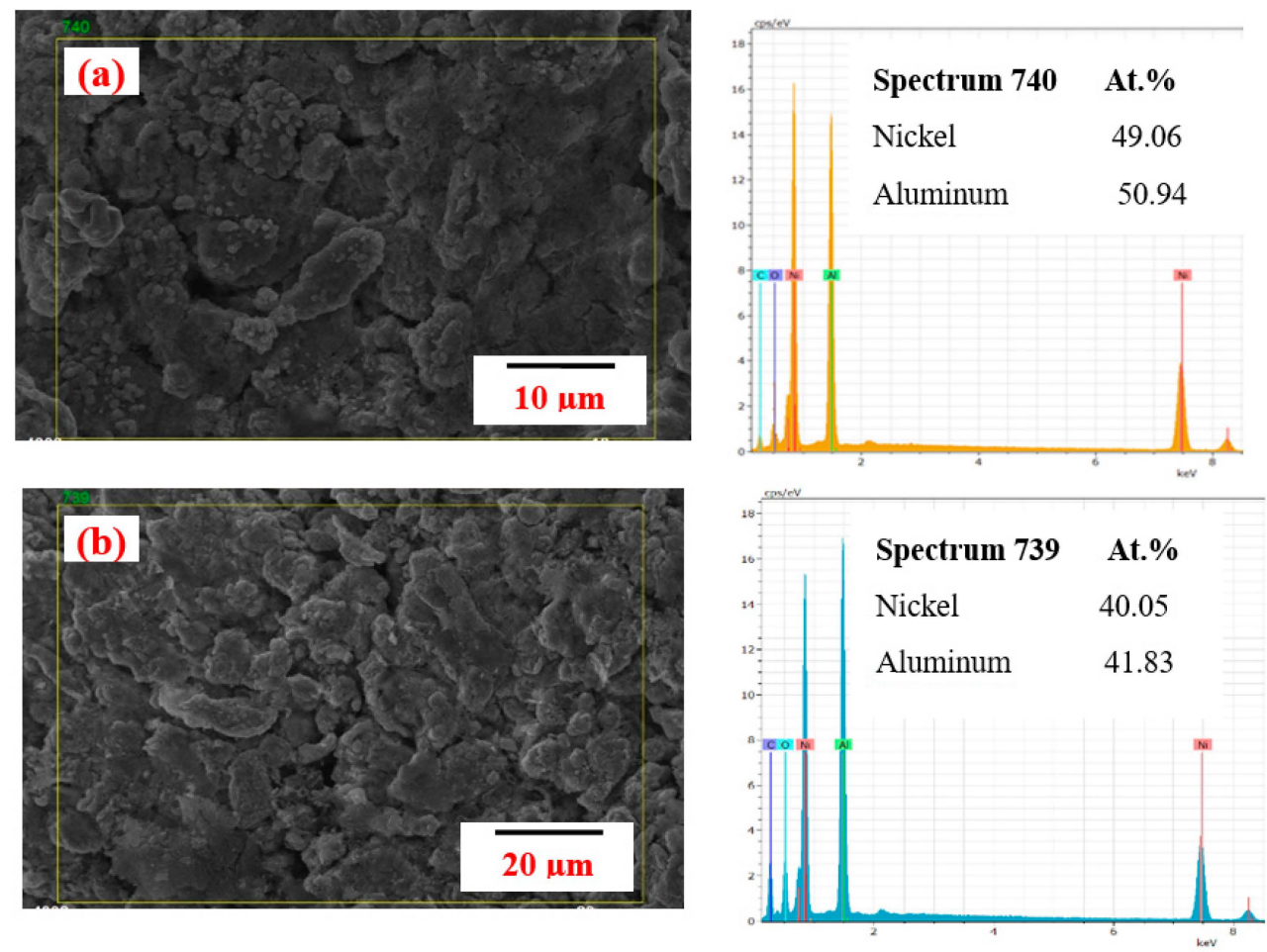

Figure 12. SEM/EDS analysis results of quenched samples from $\mathrm{Ni}+\mathrm{Al}$ (a) and $\mathrm{Ni}+\mathrm{Al}+1 \% \mathrm{CNT}$ (b) systems at $873 \mathrm{~K}, \mathrm{~V}_{\mathrm{h}}=600 \mathrm{~K} \mathrm{~min}^{-1}, \mathrm{t}_{\mathrm{MA}}=5 \mathrm{~min}, \mathrm{t}_{\mathrm{UA}}=25 \mathrm{~min}$.

It should be noted that, according to literature data, $\mathrm{Ni}_{3} \mathrm{Al}$ phase formation was also observed via solid + liquid mechanism [29]; in addition, experimental studies of another work [30] indicate that $\mathrm{Ni}_{3} \mathrm{Al}$ formation strongly depends on the change in the particle size of nickel powder. In particular, the decrease in nickel particle size as a result of MUA processing promotes the formation of the $\mathrm{Ni}_{3} \mathrm{Al}$ phase according to the $\mathrm{NiAl}+2 \mathrm{Ni}>\mathrm{Ni}_{3} \mathrm{Al}$ scheme.

\subsection{The Calculation of Effective Activation Energy of the Ni + Al Reaction by Kissinger Method}

The variation of effective activation energy values (Equation (1)) estimated for the exothermic interaction between metals under the MUA agitation is presented in Table 3. The calculation is based on the shift of characteristic temperatures of the $\mathrm{Ni}+\mathrm{Al}$ exothermic reaction versus heating rate (Figure 13).

Table 3. The effective activation energy values for the $\mathrm{Ni}+\mathrm{Al}$ reaction in the different systems.

\begin{tabular}{|c|c|c|}
\hline \multirow[b]{2}{*}{$t_{M A}$, Min } & \multicolumn{2}{|c|}{ Effective Activation Energy, $E_{a}\left(\mathrm{~kJ} \mathrm{~mol}^{-1}\right)$} \\
\hline & $\begin{array}{c}\mathrm{Ni}+\mathrm{Al} \\
\mathrm{t}_{\mathrm{UA}}=25 \mathrm{~min}\end{array}$ & $\begin{array}{c}\mathrm{Ni}+\mathrm{Al}+1 \% \mathrm{CNT} \\
\mathrm{t}_{\mathrm{UA}}=25 \mathrm{~min}\end{array}$ \\
\hline 0 & $218 \pm 13$ & $148 \pm 12$ \\
\hline 1 & $120 \pm 11$ & $129 \pm 8$ \\
\hline 3 & $229 \pm 9$ & $172 \pm 9$ \\
\hline 5 & $183 \pm 5$ & $297 \pm 9$ \\
\hline
\end{tabular}




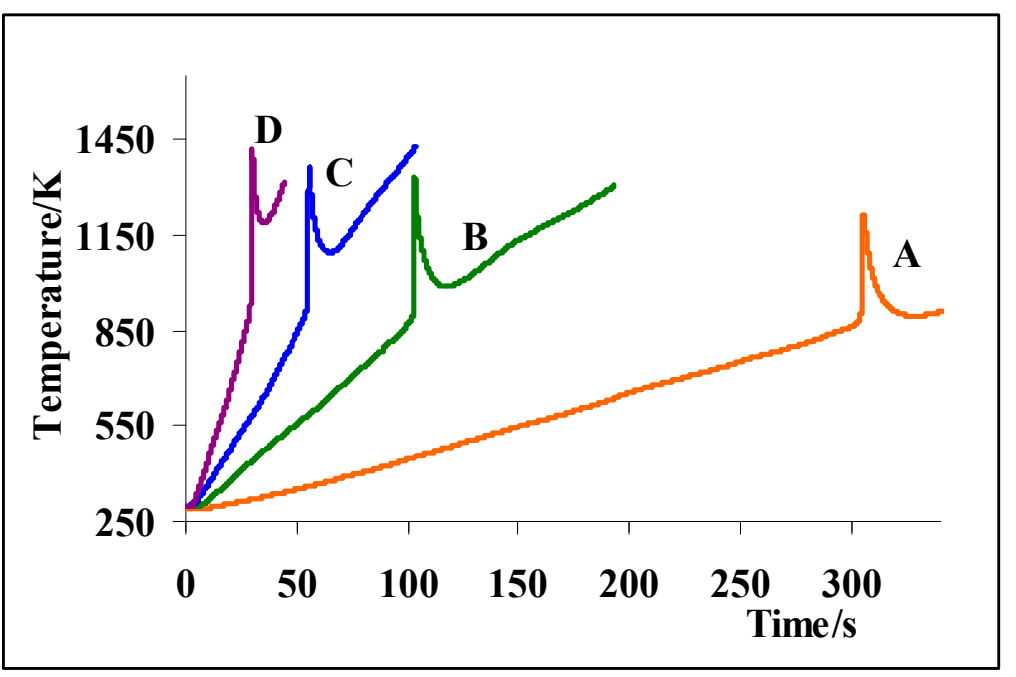

Figure 13. Heating curves of $\mathrm{UA}$ agitated 1 min mechano-activated $\mathrm{Ni}+\mathrm{Al}+1 \% \mathrm{CNT}$ mixture at different heating rates: $\mathrm{A}-\mathrm{V}_{\mathrm{h}}=100 \mathrm{~K} \mathrm{~min}^{-1}, \mathrm{~B}-300 \mathrm{~K} \mathrm{~min}^{-1}, \mathrm{C}-600 \mathrm{~K} \mathrm{~min}^{-1}, \mathrm{D}-1200 \mathrm{~K} \mathrm{~min}^{-1}$.

The increase in the MA duration of the MUA mixtures was accompanied first by a decrease in the $E_{a}$ activation energy, then by an increase, which was caused by the expansion of the specific surface area of the particles in the case of short MA processing and by the formation of aluminum agglomerates in the case of a higher duration of MA. The behavior of the activation energy in the studied systems is in harmony with the change in the interaction mechanism from solid + liquid $\left(t_{\mathrm{MA}}=0 \mathrm{~min}, 1 \mathrm{~min}\right)$ to solid + solid $\left(t_{\mathrm{MA}}=3 \mathrm{~min}, 5 \mathrm{~min}\right)$. The addition of CNTs had a significant effect on the activation energy of the non-mechano-activated mixtures, which was due to the change in the reaction mechanism by shifting the interaction process to the lower temperature range. A decrease in activation energy value was observed in the $\mathrm{Ni}+\mathrm{Al}+1 \% \mathrm{CNT}$ system under MA and UA influence for $1 \mathrm{~min}$ activated mixtures, but a further increase in the MA duration increased the activation energy regardless of the UA processing.

The activation energy values indicated that the effect of UA in the samples mechanoactivated up to one minute was significant in terms of particle size reduction, mixture homogenization, and exothermicity of the interaction. The latter is the result of acoustic cavitation at the surface, which generates high-velocity microjets of liquid that invade the surface, causing surface erosion, defects, and localized heating [31]. Increasing the duration of MA led to certain structural changes for the precursors; therefore, the exothermicity of the peak was lower, although the process was stimulated to be initiated at a lower temperature. For comparison, the ultrasonic activation of $1 \mathrm{~min}$ mechano-activated mixtures had approximately the same effect as the $1 \%$ CNT addition. In the case of a long duration of mechano-activation, it was necessary to apply ultrasound energy of a higher intensity for sufficient dispersion of the particles.

A comparative overview allowed us to comment on the strong dependence of microstructure evolution on mechanical and ultrasonic agitation. For example, intense HEBM (694 rpm, 40:1 ball-powder ratio, $6 \mathrm{~mm}$ steel balls as a milling media) resulted in the formation of a fine lamellar composite structure and a decrease in reaction onset temperature up to $573 \mathrm{~K}$ after $5 \mathrm{~min} \mathrm{MA}$ [32]. It was obvious that the interaction started during the milling and would not achieve the homogeneous phase and microstructure formation, as well as an accurate determination of the activation energy value. However, at certain MA and UA conditions, it will be possible to avoid new phase formation during the agitation and achieve the homogeneous dispersion of metallic particles. For the temperature range 923-1123 K, effective activation energy value was calculated to be $155 \mathrm{~kJ} \mathrm{~mol}^{-1}$ for non-activated mixtures by HSTS method for finer metal precursors, but by electrothermal explosion method for non-activated Ni-Al mixture, $\sim 200 \mathrm{~kJ} \mathrm{~mol}^{-1}$ was obtained [33], which is in accordance with the current work. In the current research, 25 min UA treated mixtures under 1 min 
MA demonstrated a decrease in apparent activation energy with and without the CNT addition. Ultrasound-assisted electrocatalyst preparation reported in [34] demonstrated the UA influence on commercially available alloys at high-intensity ultrasound (HIUS) processing in both water and ethanol. AlNi intermetallic particles modified under HIUS in water and ethanol-water mixture were not expected to possess improved electrocatalytic properties compared to unmodified AlNi particles caused by surface passivation via metal oxide (surface areas were 125 and $48 \mathrm{~m}^{2} \mathrm{~g}^{-1}$, respectively). This proves the necessity of preliminary ultrasound agitation of precursors, but not the alloy, and the necessity of the careful selection of UA media (not to cause oxidation of the metal's or alloy's surface). In the presence of ethanol, it was possible to avoid additional oxidation during cavitation, but limited segregation of particles was feasible. Overall, the simultaneous utilization of MA and UA enhances the liquid-surface mass transport and the reactivity of a nickel and aluminum mixture as reagents for the synthesis of intermetallics.

\section{Conclusions}

Through the influence of mechano-ultrasonic activation and carbon nanotubes as nanoadditives, the interaction pathway of nickel-aluminum powder mixture, phase, and structure formation peculiarities at high heating rates were revealed. The optimum conditions for MUA processing were deduced ( 25 min UA for 1 min MA mixtures), demonstrating the relevance of UA treatment for MA mixtures over non-mechano-activated ones and the expediency of simultaneous application of both mechanical and ultrasonic activation, instead of the separate application of each of these procedures. Along with the microstructural homogenization of the precursor mixture, MA for up to 3 min decreased the size of nickel and aluminum crystallites under the influence of UA without changing the phase composition of the initial mixtures. The increase in the heating rate shifted the characteristic temperatures of single-stage exothermic interaction to the higher region for the non-mechano-activated, mechano-activated (1, 3, $5 \mathrm{~min})$, and CNT (1 $\mathrm{wt} \%)$ containing mixtures under UA agitation. The change in the interaction mechanism from solid-liquid (non-MA, 1 min MA mixtures) to solid-solid ( 3 min MA, 5 min MA, CNT containing mixtures) altered the phase composition of the products and accompanied the formation of $\mathrm{NiAl}+\mathrm{Ni}_{3} \mathrm{Al}$ mixture $(\mathrm{s}+\mathrm{l})$ or pure $\mathrm{NiAl}(\mathrm{s}+\mathrm{s})$ after the exothermic interaction. The mutual MUA agitation shifted the heating curves to a lower temperature range, and the addition of $\mathrm{CNT}$ led to a decrease in the reaction initiation temperature, demonstrating the beneficial effect of MUA and CNT on the initiation of interaction. The effective activation energy values for the $\mathrm{Ni}+\mathrm{Al}$ exothermic reactions showed that the lower $\mathrm{E}_{\mathrm{a}}$ values were received for the $\mathrm{Ni}+\mathrm{Al}$ and $\mathrm{Ni}+\mathrm{Al}+1 \% \mathrm{CNT}$ systems under 1 min MA and 25 min UA influence. Hence, increasing the duration of MA under UA led to certain structural changes in the precursors; therefore, the exothermicity of the peak was weaker, although the process was stimulated to be initiated at a lower temperature.

Supplementary Materials: The following supporting information can be downloaded at: https: //www.mdpi.com/article/10.3390/met12030436/s1, Figure S1: SEM (a) and EDS (b) images of $\mathrm{Ni}+\mathrm{Al}$ mixture after 25 min ultrasonic activation; Figure S2: SEM images of $\mathrm{Ni}+\mathrm{Al}$ mixtures; $\mathrm{t}_{\mathrm{MA}}=0 \mathrm{~min}, \mathrm{t}_{\mathrm{UA}}=0 \min (\mathrm{a}), \mathrm{t}_{\mathrm{MA}}=0 \mathrm{~min}, \mathrm{t}_{\mathrm{UA}}=25 \mathrm{~min}(\mathrm{~b}), \mathrm{t}_{\mathrm{MA}}=5 \mathrm{~min}, \mathrm{t}_{\mathrm{UA}}=0 \min (\mathrm{c}), \mathrm{t}_{\mathrm{MA}}=5 \mathrm{~min}$, $\mathrm{t}_{\mathrm{UA}}=25 \mathrm{~min}(\mathrm{~d})$; Figure S3: EDS analysis results of the quenched samples from $\mathrm{Ni}+\mathrm{Al}$ mixtures at $1473 \mathrm{~K}, \mathrm{~V}_{\mathrm{h}}=600 \mathrm{~K} \mathrm{~min}^{-1}, \mathrm{t}_{\mathrm{MA}}=5 \mathrm{~min}, \mathrm{t}_{\mathrm{UA}}=25 \mathrm{~min}$.

Author Contributions: Conceptualization, H.K., K.N., M.Z. and S.A.; Data curation, S.A.; Funding acquisition, S.A.; Investigation K.N., M.Z., L.A. and O.V.; Methodology, H.K., K.N. and S.A.; Resources, S.A.; Supervision, S.A.; Visualization, H.K.; Writing-original draft, H.K.; Writing-review \& editing, H.K. and S.A. All authors have read and agreed to the published version of the manuscript.

Funding: This research was funded by the Committee of Science Ministry of Education, Science, Culture, and Sports of the Republic of Armenia (grant numbers 18BL-011, 20TTWS-2F040, 20RF-154), the Estonian Research Council (Sofiya Aydinyan, grant number PSG220), and the European Regional Development Fund project TK141. 


\section{Institutional Review Board Statement: Not applicable.}

Informed Consent Statement: Not applicable.

Data Availability Statement: Not applicable.

Conflicts of Interest: The authors declare no conflict of interest.

\section{References}

1. Czeppe, T.; Wierzbinski, S. Structure and mechanical properties of $\mathrm{NiAl}$ and $\mathrm{Ni}_{3} \mathrm{Al}$-based alloys. Int. J. Mech. Sci. 2000, 42, 1499-1518. [CrossRef]

2. Portnoy, V.K.; Blinov, A.M.; Tomilin, I.A.; Kuznetsov, V.N.; Kulik, T. Formation of nickel aluminides by mechanical alloying and thermodynamics of interaction. J. Alloys Compd. 2002, 336, 196-201. [CrossRef]

3. Morsi, K. Reaction synthesis processing of Ni-Al intermetallic materials. Mater. Sci. Eng. A 2001, 299, 1-15. [CrossRef]

4. Suryanarayana, C. Mechanical alloying and milling. Prog. Mater. Sci. 2001, 46, 1-184. [CrossRef]

5. Takacs, L. Self-sustaining reactions induced by ball milling. Prog. Mater. Sci. 2002, 47, 355-414. [CrossRef]

6. Philpot, K.A.; Munir, Z.A.; Holt, J.B. An investigation of the synthesis of nickel aluminides through gasless combustion. J. Mater Sci. 1987, 22, 159-169. [CrossRef]

7. Kim, J.K.; Chung, D.S. Fabrication of metal/intermetallic compound laminate composites by thin foil hot press process. Solid State Phenom. 2007, 124, 1099-1102. [CrossRef]

8. Lebrat, J.P.; Varma, A.; McGinn, P.J. Mechanistic studies in combustion synthesis of $\mathrm{Ni}_{3} \mathrm{Al}_{\text {and }} \mathrm{Ni}_{3} \mathrm{Al}-$ matrix composites. J. Mater Res. 1994, 9, 1184-1192. [CrossRef]

9. Li, L.; Lai, M.O. Formation of new materials in the solid state by mechanical alloying. Mater. Des. 1995, 16, 33-39. [CrossRef]

10. Krasnowski, M.; Gierlotka, S.; Ciołek, S.; Kulik, T. Nanocrystalline NiAl intermetallic alloy with high hardness produced by mechanical alloying and hot-pressing consolidation. Adv. Powder Technol. 2019, 30, 1312-1318. [CrossRef]

11. Awotunde, M.A.; Okoro, M.A.; Adegbenjo, A.O.; Shongwe, B.M.; Tshephe, T.S.; Olubambi, P.A. The effect of alloying additions on the mechanical properties of nickel aluminide NiAl-A review. In Proceedings of the 2018 IEEE 9th International Conference on Mechanical and Intelligent Manufacturing Technologies (ICMIMT), Cape Town, South Africa, 10-13 February 2018; IEEE: Piscataway, NJ, USA, 2018; pp. 64-68. [CrossRef]

12. Filimonov, V.Y.; Loginova, M.V.; Ivanov, S.G.; Sitnikov, A.A.; Yakovlev, V.I.; Sobachkin, A.V.; Negodyaev, A.Z.; Myasnikov, A.Y. Peculiarities of phase formation processes in activated Ti+Al powder mixture during transition from combustion synthesis to high-temperature annealing. Combust. Sci. Technol. 2019, 192, 457-470. [CrossRef]

13. Beyhaghi, M.; Kiani-Rashid, A.; Khaki, J.V.; Kashefi, M.; Jonsson, S. Influences of mechanical activation and heating rate on reaction processes in combustion synthesis of $\mathrm{NiAl}-\mathrm{Al}_{2} \mathrm{O}_{3}$ composites. Powder Technol. 2019, 346, 237-247. [CrossRef]

14. Mason, B.A.; Sippel, T.R.; Groven, L.J.; Gunduz, I.E.; Son, S.F. Combustion of mechanically activated Ni/Al reactive composites with microstructural refinement tailored using two-step milling. Intermetallics 2015, 66, 88-95. [CrossRef]

15. Khodaei, M. Characterization of $\mathrm{Al}_{2} \mathrm{O}_{3}$ in $\mathrm{Fe}_{3} \mathrm{Al}-30$ vol. $\% \mathrm{Al}_{2} \mathrm{O}_{3}$ nanocomposite powder synthesized by mechanochemical process. J. Nanostruct. 2020, 10, 456-462. [CrossRef]

16. Kochetov, N.A.; Seplyarsii, B.S. SHS in the Ni-Al System: Influence of Green Density and Mechanoactivation. Int. J. SelfPropagating High-Temp. Synth. 2021, 30, 115-118. [CrossRef]

17. Suslick, K.S.; Casadonte, D.J.; Green, M.L.H.; Thompson, M.E. Effects of high intensity ultrasound on inorganic solids. Ultrasonics 1987, 25, 56-59. [CrossRef]

18. Li, Z.; Zhuang, T.; Dong, J.; Wang, L.; Xia, J.; Wang, H.; Cui, X.; Wang, Z. Sonochemical fabrication of inorganic nanoparticles for applications in catalysis. Ultrason. Sonochem. 2021, 71, 105384. [CrossRef]

19. Doh, S.G.; Kim, E.B.; Lee, B.H.; Oh, J.H. Characteristics and synthesis of Cu-Ni ferrite nanopowders by coprecipitation method with ultrasound irradiation. J. Magn. Magn. Mater. 2004, 272, 2238-2240. [CrossRef]

20. Liu, Z.; Rakita, M.; Xu, W.; Wang, X.; Han, Q. Ultrasound assisted combustion synthesis of TiC in Al-Ti-C system. Ultrason. Sonochem. 2015, 27, 631-637. [CrossRef]

21. Dulle, J.; Nemeth, S.; Skorb, E.V.; Irrgang, T.; Senker, J.; Kempe, R.; Fery, A.; Andreeva, D.V. Sonochemical activation of Al/Ni hydrogenation catalyst. Adv. Funct. Mater. 2012, 22, 3128-3135. [CrossRef]

22. Nazaretyan, K.T.; Kirakosyan, H.V.; Aydinyan, S.V.; Zakaryan, M.K.; Abovyan, L.S.; Kulak, M.; Khina, B. The influence of high-energy ball milling and nanoadditives on the kinetics of heterogeneous reaction in Ni-Al system. In IOP Conference Series: Materials Science and Engineering; IOP Publishing: Bristol, UK, 2021; Volume 1140, p. 012052. [CrossRef]

23. Zakaryan, M.; Nazaretyan, K.; Aydinyan, S.; Kharatyan, S. Joint Reduction of $\mathrm{NiO} / \mathrm{WO}_{3} \mathrm{Pair}_{\text {and }} \mathrm{NiWO} 4$ by $\mathrm{Mg}+\mathrm{C} \mathrm{Combined}$ Reducer at High Heating Rates. Metals 2021, 11, 1351. [CrossRef]

24. Kamboj, N.; Aghayan, M.; Rubio-Marcos, F.; Nazaretyan, K.; Rodríguez, M.A.; Kharatyan, S.; Hussainova, I. Nanostructural evolution in mesoporous networks using in situ high-speed temperature scanner. Ceram. Int. 2018, 44, 12265-12272. [CrossRef]

25. Zakaryan, M.K.; Nazaretyan, K.T.; Aydinyan, S.V.; Kharatyan, S.L. NiO reduction by Mg+C combined reducer at high heating rates. J. Therm. Anal. Calorim. 2020, 146, 1811-1817. [CrossRef] 
26. Kirakosyan, H.; Nazaretyan, K.; Aydinyan, S.; Kharatyan, S. The Mechanism of Joint Reduction of $\mathrm{MoO}_{3}$ and $\mathrm{CuO}$ by Combined $\mathrm{Mg} / \mathrm{C}$ Reducer at High Heating Rates. J. Compos. Sci. 2021, 5, 318. [CrossRef]

27. Blaine, R.L.; Kissinger, H.E. Homer Kissinger and the Kissinger equation. Thermochim. Acta 2012, 540, 1-6. [CrossRef]

28. Gates-Rector, S.; Blanton, T. The powder diffraction file: A quality materials characterization database. Powder Diffr. 2019, 34, 352-360. [CrossRef]

29. Biswas, A.; Roy, S.K.; Gurumurthy, K.R.; Prabhu, N.; Banerjee, S. A study of self-propagating high-temperature synthesis of NiAl in thermal explosion mode. Acta Mater. 2002, 50, 757-773. [CrossRef]

30. Yeh, C.L.; Sung, W.Y. Combustion synthesis of $\mathrm{Ni}_{3} \mathrm{Al}$ intermetallic compound in self-propagating mode. J. Alloys Compd. 2004, 384, 181-191. [CrossRef]

31. Mao, Q.; Coutris, N.; Rack, H.; Fadel, G.; Gibert, J. Investigating ultrasound-induced acoustic softening in aluminum and its alloys. Ultrasonics 2022, 102, 106005. [CrossRef]

32. Nepapushev, A.A.; Kirakosyan, K.G.; Moskovskikh, D.O.; Kharatyan, S.L.; Rogachev, A.S.; Mukasyan, A.S. Influence of highenergy ball milling on reaction kinetics in the Ni-Al system: An electrothermorgaphic study. Int. J. Self-Propagating High-Temp. Synth. 2015, 24, 21-28. [CrossRef]

33. Rogachev, A.S.; Shkodich, N.F.; Vadchenko, S.G.; Baras, F.; Kovalev, D.Y.; Rouvimov, S.; Nepapushev, A.A.; Mukasyan, A.S. Influence of the high energy ball milling on structure and reactivity of the $\mathrm{Ni}+\mathrm{Al}$ powder mixture. J. Alloys Compd. 2013, 577, 600-605. [CrossRef]

34. Cherepanov, P.V.; Ashokkumar, M.; Andreeva, D.V. Ultrasound assisted formation of Al-Ni electrocatalyst for hydrogen evolution. Ultrason. Sonochem. 2015, 23, 142-147. [CrossRef] [PubMed] 